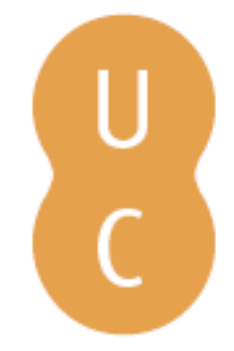

\title{
Rompalina
}

\section{Dinâmica de transformação de uso e ocupação do solo em espaço rural a partir de fotointerpretação no período 1965-2010}

\author{
Autor(es): $\quad$ Monteiro, Mário; Tavares, Alexandre Oliveira; Serra, Rita \\ Publicado por: Imprensa da Universidade de Coimbra \\ URL \\ persistente: URI:http://hdl.handle.net/10316.2/37055 \\ DOI: $\quad$ DOI:http://dx.doi.org/10.14195/978-989-26-0983-6_2 \\ Accessed : $\quad$ 26-Apr-2023 11:36:21
}

A navegação consulta e descarregamento dos títulos inseridos nas Bibliotecas Digitais UC Digitalis, UC Pombalina e UC Impactum, pressupõem a aceitação plena e sem reservas dos Termos e Condições de Uso destas Bibliotecas Digitais, disponíveis em https://digitalis.uc.pt/pt-pt/termos.

Conforme exposto nos referidos Termos e Condições de Uso, o descarregamento de títulos de acesso restrito requer uma licença válida de autorização devendo o utilizador aceder ao(s) documento(s) a partir de um endereço de IP da instituição detentora da supramencionada licença.

Ao utilizador é apenas permitido o descarregamento para uso pessoal, pelo que o emprego do(s) título(s) descarregado(s) para outro fim, designadamente comercial, carece de autorização do respetivo autor ou editor da obra.

Na medida em que todas as obras da UC Digitalis se encontram protegidas pelo Código do Direito de Autor e Direitos Conexos e demais legislação aplicável, toda a cópia, parcial ou total, deste documento, nos casos em que é legalmente admitida, deverá conter ou fazer-se acompanhar por este aviso.

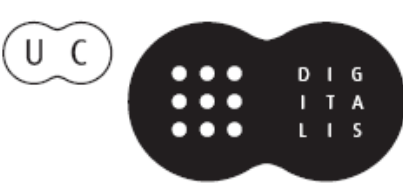




\section{$\forall$ \\ TAS DAS I JORNADAS LUSÓFONAS DE CIÊNCIAS E TECNOLOGIAS DE INFORMAÇÃO GEOGRÁFICA}

Editores

José Gomes dos Santos

Cidália Fonte

Rui Ferreira de Figueiredo

Alberto Cardoso

Gil Gonçalves

José Paulo Almeida

Sara Baptista 


\title{
ARTIGO 2 \\ DINÂMICA DE TRANSFORMAÇÃO DE USO E OCUPAÇÃo DO SOLO EM ESPAÇO RURAL A PARTIR DE FOTOINTERPRETAÇÃO NO PERÍODO 1965-2010
}

\author{
MONTEIRO, Mário ${ }^{1}$ E TAVARES, Alexandre Oliveira ${ }^{1,2}$ E SERRA, Rita ${ }^{2}$
}

\begin{abstract}
${ }^{1}$ Departamento de Ciências da Terra - Faculdade de Ciências e Tecnologia da Universidade de Coimbra (Portugal); Largo Marquês de Pombal, 3000-272 Coimbra, Portugal; Tel: +351 239860500 ; Fax: +351 239860 501; email: mariodsmonteiro@gmail.com; atavares@ci.uc.pt

2 Centro de Estudos Sociais da Universidade de Coimbra (Portugal); Colégio de S. Jerónimo; Largo D. Dinis, Apartado 3087, 3000-995 Coimbra, Portugal;Tel: +351 239855 570; Fax: +351 239855 589; email: atavares@ci.uc.pt; ritaserra@ces.uc.pt
\end{abstract}

\section{RESUMO}

Os processos de alteração de uso e ocupação do solo apresentam uma variedade de trajectórias, dependendo das condições locais, do contexto regional e de influências externas. O estudo apresentado é uma avaliação das mudanças no uso e ocupação do solo, do ponto de vista espacial e temporal, no período 1965-2010. A área em análise corresponde genericamente a um espaço rural localizado no concelho da Lousã. Apoiado por uma colecção de imagens para cinco períodos (1965, 1974, 1983, 1995 e 2010), os indicadores de transformação foram analisados em termos do grau de estabilidade (GE), que expressa a proporção total da paisagem que não evidenciou qualquer transição de uso. As transições espaciais e temporais envolvem um aumento significativo das áreas urbanas com um tecido urbano descontínuo, uma redução dos espaços agrícolas e a rotação significativa da ocupação e tipo de floresta. A metodologia aplicada evidenciou quatro períodos de transformação, mostrando uma evolução distinta no uso e ocupação do solo, em que a consolidação urbana está presente de forma consistente, em conjunto com a rotação da tipologia da floresta, 
envolvendo a degradação florestal e o aumento das áreas agro-florestais ou das áreas com vegetação escassa ou ardidas.

\title{
PALAVRAS-CHAVE
}

Uso e ocupação do solo, Forçadores de transformação, Grau de estabilidade, Rotação da floresta, Imagens de satélite.

DYNAMIC TRANSFORMATION OF LAND USE AND OCCUPATION IN RURAL AREAS FROM PHOTOINTERPRETATION IN THE PERIOD 1965-2010

\begin{abstract}
The processes of change in land use have a variety of trajectories, depending on local conditions, regional context and external influences. The study is an analysis of the changes in land use, in terms of space and time, in a rural area, for the period 1965-2010. The analyzed area is a part of the Lousã County, in central Portugal. Supported by a collection of images for five periods (1965, 1974, 1983, 1995 and 2010), the indicators of transformation were analyzed in terms of the stability grade (SG), which expresses the total proportion of the landscape that showed no transition use. The spatial and temporal transitions involve a significant increase in urban areas with a discontinuous urban fabric, a reduction in agricultural areas and significant rotation of occupation and type of forest. The methodology presented four periods of transformation, showing a distinct evolution in land use where the urban consolidation is consistently present, together with the rotation of the typology of the forest, involving forest degradation and the increase of agro-forestry areas or areas with sparse vegetation or burnt.
\end{abstract}

\section{KEYWORDS}

Land use, Transformation forcers, Stability grade, Forest routing, Satellite imagery.

\section{INTRODUÇÃO}

Segundo Verburg et al. (2010) as modificações no uso e ocupação do solo apresentam uma variedade de trajectórias, dependendo das condições locais, do contexto regional e dos factores externos Diferentes estudos destacam as interacções que envolvem forçadores socioeconómicos e condições biofísicas (ASPINALL, 2004; BRAIMOH \& ONISHI, 2007; TAVARES et al., 2012; LI et al. , 2013). 
Conforme realçado por Hietel et al. (2004), as alterações no uso e ocupação do solo em áreas rurais ocorrem dentro dos limites físicos da paisagem e pressupõem um conhecimento das dinâmicas em curso e das suas características resultantes (CLAESSENS et al., 2009; DOMON, 2011). Vários estudos avaliam a dinâmica da paisagem rural através da representação de padrões e da evolução dos indicadores (HASSE \& LATHROP, 2003; BODESMO et al., 2012), tendo outros autores apontado que as trajectórias de uso e ocupação do solo emergem da concorrência entre as áreas agrícolas e florestais, como enfatizado por Rudel et al. (2005), Lasanta et al. (2006) e Abdullah e Nakagoshi (2008).

As transformações de uso e ocupação do solo são avaliadas por diferentes métodos e fontes documentadas (ASPINALL, 2004; BRAIMOTH, 2006; WENTZ et al., 2006), e especificamente pelo uso de técnicas de fotointerpretação (HARA et al., 2005; PAN \& ZHAO, 2007; ROZENSTEIN \& KARNIELI, 2011). O uso de imagens de satélite para interpretação tornou possível integrar conjuntos de imagens com vários períodos de observação, obtidas a partir de fontes diversas e utilizando diferentes escalas. A reconstituição do trajecto de transformação usando fotografias aéreas e imagens de satélite, de acordo com os princípios de classificação uniforme e recursos de validação de campo têm sido explorados por diversos autores (TAPIADOR \& CASANOVA, 2003; CATALAN et al., 2008; KOLIOS \& STYLIOS, 2013).

A detecção da dinâmica de transformação temporal no uso e ocupação do solo podem ser divididos em três passos principais: pré-classificação unitária (classificação de imagem única); classificação comparativa (comparação entre imagens de diferentes anos) e pós-classificação (comparação global do processo de transformação), como demonstrado por Manandhar et al. (2010) e Tavares et al. (2012).

Em Portugal, diferentes estudos têm salientado os processos de alteração de uso do solo rural (CASTANHEIRA \& ARANHA, 2004; FREIRE et al., 2009; JONES et al., 2011; POÇAS et al., 2011; NUNES et al., 2011; AZEVEDO et al., 2011; DIOGO \& KOOMEN, 2012; FIGUEIREDO et al., 2012).

O objectivo principal deste trabalho é analisar as mudanças espaciais 
e temporais do uso e ocupação do solo numa área montanhosa rural, durante o período 1965-2010. Assim, pretende-se responder às seguintes questões:

- Quais são as transformações espaciais e temporais de uso e ocupação do solo?

- Quais são as mudanças gerais de uso e ocupação do solo e qual é a evolução do grau de estabilidade?

- Que forçadores sistemáticos e casuísticos podem ser apontados nas transformações de uso e ocupação do solo?

\section{DESCRIÇÃo DA ÁREA DE ESTUDO}

A área de estudo situa-se no interior centro de Portugal, na Serra da Lousã, no município da Lousã (Figura 1).

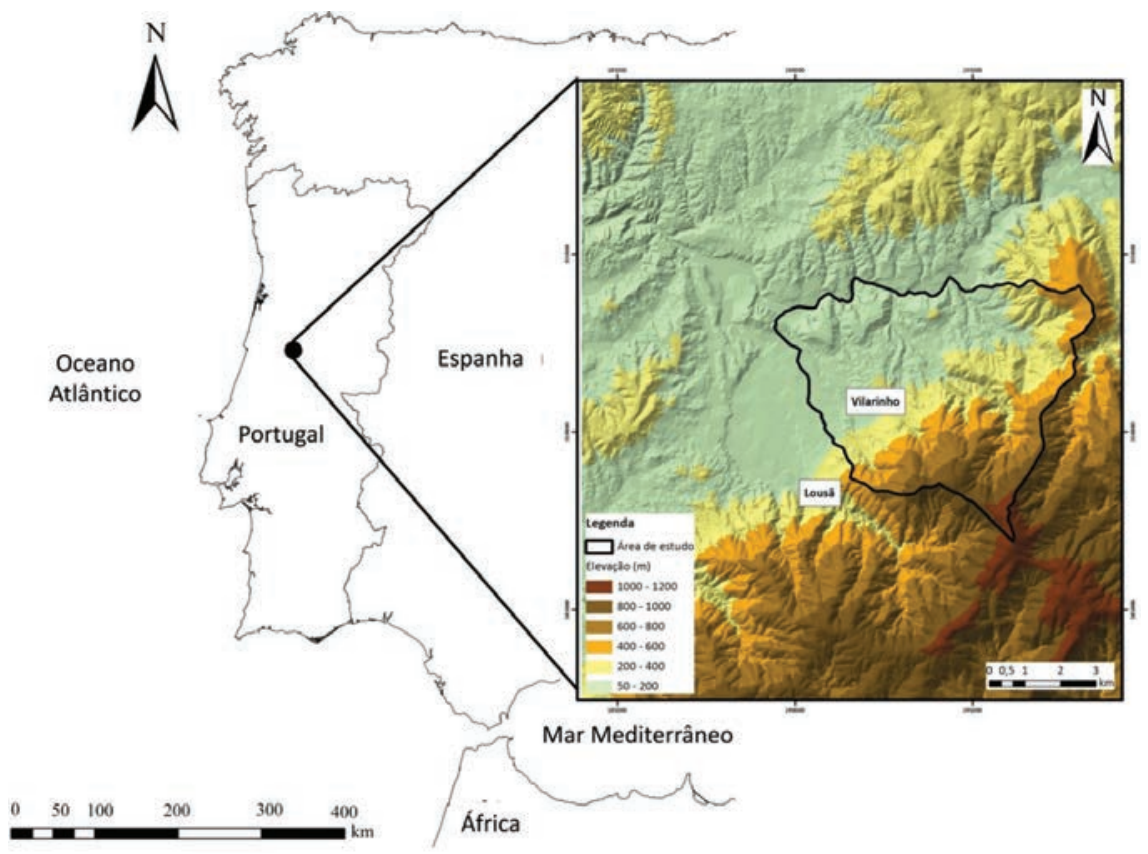

Figura 1 - Localização da área de estudo 
Em termos morfológicos a área é marcada pelo relevo da serra da Lousã, representada pelo levantamento de origem tectónica, com orientação geral NE-SW. A falha inversa que marca este acidente faz salientar o contraste entre os sectores sudeste e noroeste, representados, respectivamente, pelas unidades metassedimentares soerguidas e pelas unidades arenosas e conglomeráticas cretácicas e terciárias da bacia sedimentar deprimida (SOARES et al., 2007).

Os valores hipsométricos regionais variam de 50 a 1200 metros, com uma amplitude na área de estudo de $1190 \mathrm{~m}$, perto do ponto geodésico topo do Castelo de Trevim, e $70 \mathrm{~m}$ no vale do rio Ceira. Esta localização e a morfologia diferenciada podem ser observadas na Figura 1. Os declives apresentam contrastes entre vertentes com valores acima de $25^{\circ}$, em vales incisivos, em geral expostos a norte e oeste, e as vertentes com declives menos acentuados (entre 0 a 15\%) (Figura 2 -A e Figura 2 -b).
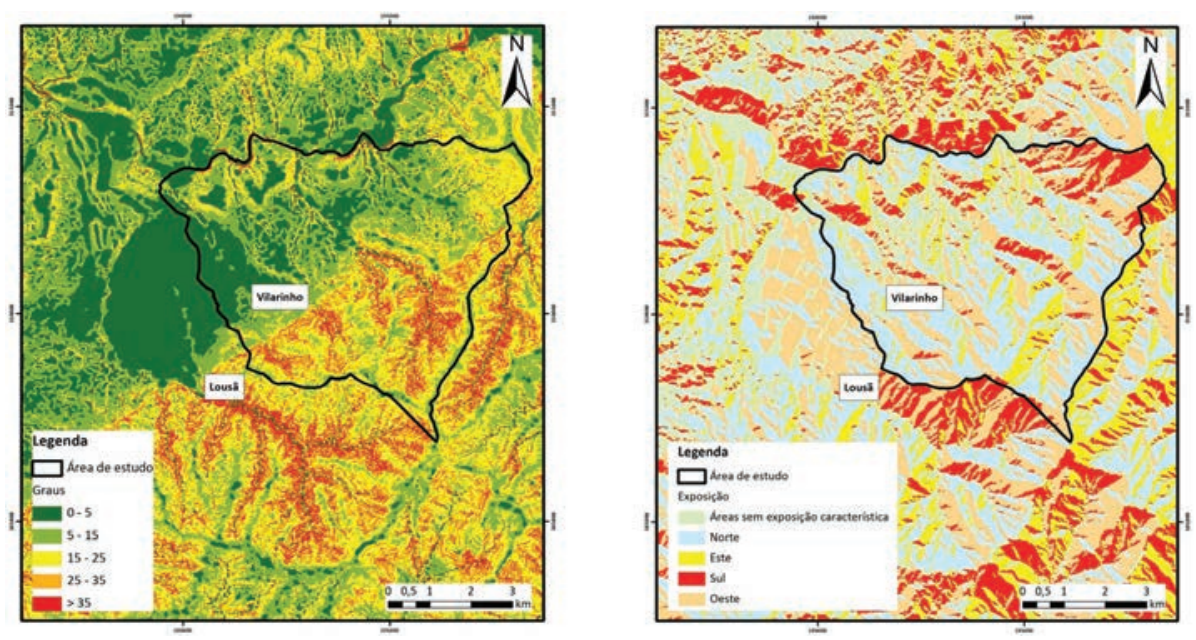

Figura 2 - Declives e exposições na área de estudo

A região apresenta um clima mediterrâneo húmido, com pouca chuva no verão, embora possa apresentar características atlânticas húmidas noutras estações. As temperaturas médias anuais oscilam entre $15^{\circ}$ e $16^{\circ}$, e a precipitação média anual varia entre 1000 e $1800 \mathrm{~mm}$. Do ponto de vista hidrográfico há que salientar o rio Ceira, que tem um regime permanente, o qual é alimentado por cursos de água efémeros. As características de 
montanha são o factor local que afecta decisivamente a distribuição de temperatura e precipitação dentro da própria área de estudo.

No que diz respeito à ocupação humana da área, o município da Lousã tem cerca de 17.604 habitantes segundo os Censos de 2011 (INE, 2012). Este valor traduz um aumento geral da população, a partir de 1970 e uma variação de 10,3\% no período 2001-2011. A maior parte da área é utilizada para agricultura e silvicultura, com alguns aglomerados populacionais.

A área de estudo abrange três freguesias, incluindo a totalidade da freguesia de Vilarinho e parte das freguesias de Lousã e Serpins, e está a cerca de $7 \mathrm{~km}$ de distância do centro da Lousã, estando contabilizados 4408 residentes. Observa-se no sector mais ocidental da área processos de crescimento peri-urbano e de incremento de infra-estruturas, nomeadamente rodoviárias.

A análise de transformação do uso e ocupação do solo é realizada em cerca de $40 \mathrm{~km}^{2}$ de área, onde estão representadas quatro pequenas bacias hidrográficas de cursos de água efémeros, que são afluentes do rio Ceira.

\section{MATERIAL E MÉTODOS}

O estudo das transformações de uso e ocupação do solo foi apoiado por um conjunto de cinco mosaicos fotográficos de diferentes períodos, entre 1965 e 2010, conforme descrito na Tabela 1. De acordo com as características iniciais das imagens, estas foram digitalizadas, georreferenciadas e manuseadas, utilizando o software ArcGis 10.2. (ESRI®).

$\mathrm{Na}$ primeira etapa, as imagens de 1965, 1974 e 1983 foram georreferenciados utilizando o software ArcGis 10.2 (ESRIß), tendo pelo menos quatro pontos em cada imagem em consideração. As imagens digitalizadas para os anos de 1965, 1974 e 1983, tinham sido previamente georreferenciadas utilizando o Sistema de coordenadas geográficas Datum_73_Hayford_Gauss_IGeoE.

As imagens digitalizadas para os anos de 1995 e 2010 foram igualmente georreferenciadas utilizando o sistema de coordenadas geográficas Datum_73_Hayford Gauss_IGeoE. 
Tabela 1 - Características das fontes de dados

\begin{tabular}{|c|c|c|c|c|c|}
\hline Data & $N^{\circ}$ fotografia & Formato & Tipo de imagem & Escala & Fonte \\
\hline 1965 & $\begin{array}{l}72 / 65 \_116 \\
72 / 65 \_118 \\
70 / 65 \_57 \\
70 / 65 \_59 \\
70 / 65 \_61 \\
67 / 65 \_59 \\
67 / 65 \_61 \\
67 / 65 \_63 \\
67 / 65 \_65\end{array}$ & Digital & Preto \& Branco & 1: 5000 & IGP \\
\hline 1974 & $\begin{array}{l}183 / 74 \_253 \\
183 / 74 \_255 \\
183 / 74 \_257 \\
182 / 74 \_174 \\
182 / 74 \_176 \\
182 / 74 \_178 \\
182 / 74 \_154 \\
182 / 74 \_156 \\
182 / 74 \_158\end{array}$ & Digital & Preto \& Branco & 1: 5000 & . \\
\hline 1983 & $\begin{array}{l}83.19 \_2525 \\
83.19 \_2527 \\
83.19 \_2529 \\
83.19 \_2530 \\
83.19 \_2532 \\
83.19 \_2533 \\
83.19 \_2535 \\
83.02 \_5246 \\
83.02 \_5247\end{array}$ & Digital & Preto \& Branco & 1: 5000 & . \\
\hline 1995 & $\begin{array}{l}\text { Ortofoto } \mathrm{n}^{\circ} 389 \\
\text { Ortofoto } \mathrm{n}^{\circ} 390 \\
\text { Ortofoto } \mathrm{n}^{\circ} 391\end{array}$ & Digital & Falsa cor & $\begin{array}{c}\left.\text { 1: } \begin{array}{lll}40 & 000 \\
(1: & 10 & 000\end{array}\right)\end{array}$ & CNIG \\
\hline 2010 & $\begin{array}{l}\text { D2420320 } \\
\text { D2420340 } \\
\text { D2420410 } \\
\text { D2420420 } \\
\text { D2420430 } \\
\text { D2420440 } \\
\text { D2520120 } \\
\text { D2520210 } \\
\text { D2520220 } \\
\text { D2520230 } \\
\text { D2520240 }\end{array}$ & Digital & Cor & & IGP \\
\hline
\end{tabular}


Tabela 2 - Termos de classificação

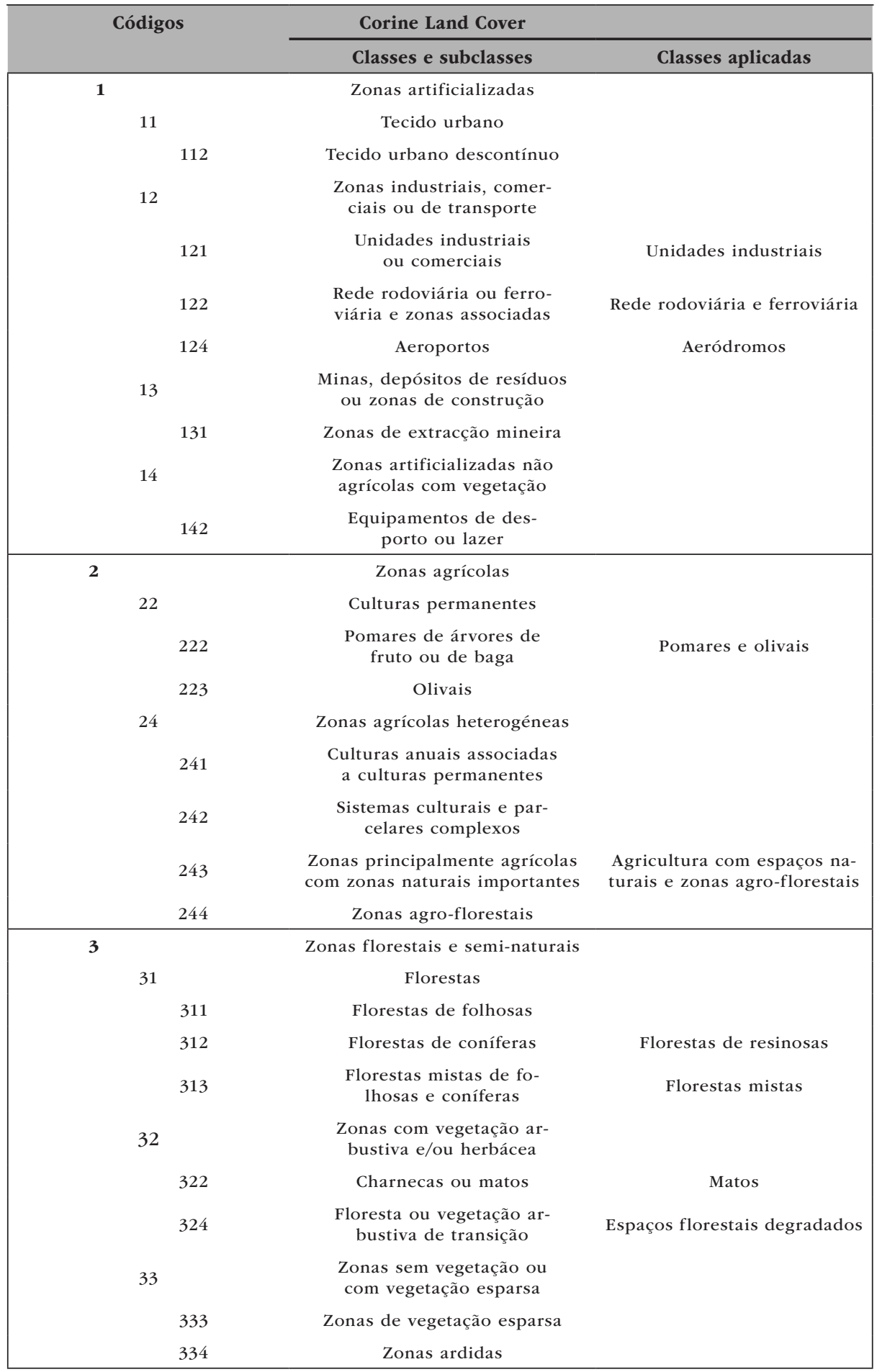


Na segunda etapa, foi desenvolvido um sistema de classificação, com base nas categorias de uso e ocupação do solo do Corine Land Cover (CLC, 1990) e identificado através de classes organizadas segundo códigos numéricos (BOSSARD et al., 2000; NERY, 2007). Para adequação à área de estudo, foram utilizadas as subclasses apresentados na Tabela 2 , tendo havido necessidade de simplificação e validação através de trabalho de campo.

Numa terceira etapa realizou-se a classificação de polígonos homogéneos de uso e ocupação do solo para cada conjunto de imagens. Foram incorporadas no sistema de informação geográfica as classes que caracterizam o uso e ocupação do solo no momento de captura da imagem (PIWOWAR, 2005; TAPIADOR \& CASANOVA, 2003). Por uma questão de coerência, todos os polígonos foram classificados com base numa escala 1:10.000 de visualização, e a menor unidade cartográfica considerada foi de 1 hectare. Cada conjunto de imagens gerou uma matriz de polígonos codificados de acordo com as diferentes classes. Para a validação do processo de classificação recorreu-se a levantamentos de campo para a imagem mais recente, e utilizaram-se, para as imagens mais antigas, informações orais e cartográficas disponibilizadas pelos Compartes dos Baldios de Vilarinho e pelo Gabinete Técnico-Florestal da Câmara Municipal da Lousã.

A fim de medir a evolução do uso e ocupação do solo, foi criada uma pós-classificação (comparação de mapa para mapa), envolvendo os conjuntos sucessivos de imagens com referências cruzadas para definir transições de cobertura de uso e ocupação do solo e do grau de estabilidade (GE) em cada período de tempo. Os mapas criados para cada ano em questão foram utilizados para gerar matrizes referentes aos períodos 1965-1974, 1974-1983, 1983-1995, 1995-2010 e uma matriz resumo 19652010. A fim de minimizar os possíveis erros de interpretação, todo o trabalho foi realizado pelo mesmo operador.

Para expressar a proporção total de área que não experimentou uma eventual transição para uma categoria diferente de uso e ocupação do solo, foi definido o indicador grau de estabilidade (GE) como mostra a equação (A1): 


$$
\mathrm{GE}=\left[\left(\mathrm{C}_{\mathrm{ix}} \mathrm{A}_{2 \ldots 7}-\mathrm{C}_{\mathrm{ix}} \mathrm{A}_{1}\right) / \mathrm{TA}\right] \times 100
$$

em que GE é o grau de estabilidade para o tipo de uso e ocupação do solo - o indicador da consistência ou a estabilidade global das classes de cobertura do solo no ano $\mathbf{A}_{1}$ para o ano $\mathbf{A}_{2 \ldots 7}, \mathrm{Cix}_{2 \ldots 7}$ é a soma das áreas das diferentes classes (ix) no ponto de tempo posterior, CixA1 é a soma das áreas das diferentes classes (ix) no ponto de tempo 1 e TA é a área total estudada $\left(\mathrm{km}^{2}\right)$.

\section{RESULTADOS}

Utilizando os métodos descritos, foi produzida uma análise e classificação sistemática do uso e ocupação do solo, como mostrado na Figura 3, durante cinco anos/momentos. A Tabela 3 apresenta as classes aplicadas no uso e ocupação do solo, o número de polígonos de cada classe e em cada ano, bem como a área e percentagem de cada classe. Dezassete diferentes classes de uso e ocupação do solo foram identificadas na área de estudo durante o período em análise, dos quais apenas duas têm uma representação resultante de processos não contínuos - casuísticas (áreas de extracção mineira e áreas ardidas). Os outputs cartográficos mostram uma grande mudança nos diferentes sectores da área, com variadas trajectórias. A análise indica algumas transições sistemáticas envolvendo um aumento de áreas com características urbanas e uma diminuição nas áreas agrícolas, nomeadamente na parte ocidental da área, assim como a transformação das várias tipologias florestais e a ocorrência episódica de incêndios florestais.

Uma observação mais detalhada das cinco representações cartográficas salienta que a mudança da paisagem é relevante, envolvendo uma transformação significativa de classes diferentes. A análise também evidencia duas sequências positivas, onde se observa o aumento do número de manchas representadas: uma que envolve os três primeiros conjuntos de imagens, e outra entre os anos de 1995 e 2010. 


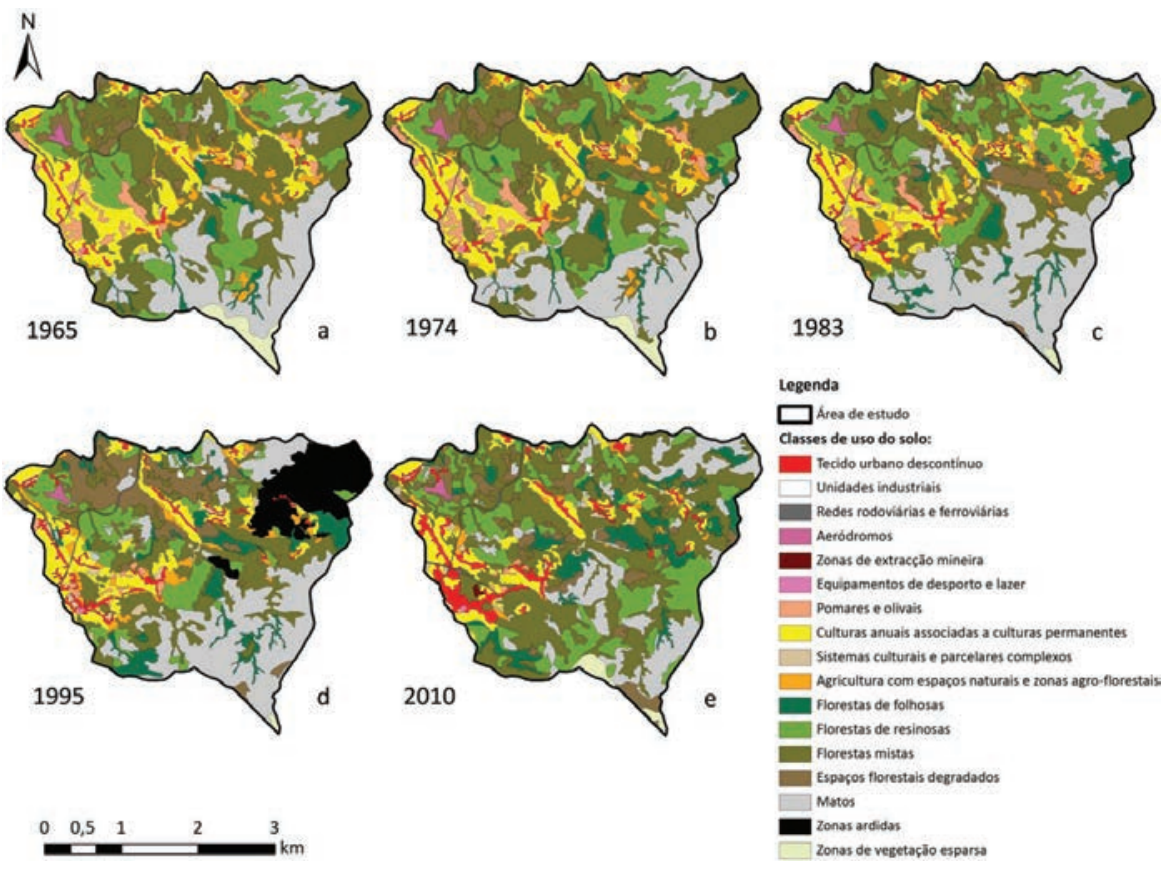

Figura 3 - Uso e ocupação do solo na área de estudo, com base na classificação de imagens por ano

No que diz respeito à área em estudo, e analisando o uso e ocupação do solo, as transformações observadas são:

- aumento do tecido urbano descontínuo, unidades industriais e rede rodoviária e ferroviária, bem como dos sistemas culturais e parcelares complexos e floresta de folhosas;

- diminuição da área com pomares e olivais, culturas anuais associados com culturas permanentes e agricultura com espaços naturais e áreas agro-florestais;

- rotação de grande parte da ocupação florestal, com transições entre floresta com espécies dominantes, floresta mista e degradada;

- consistência temporal da área ocupada por floresta de coníferas e por floresta mista, embora com modificação de espaços;

- superfície consistente ao longo do tempo ocupada pelas redes rodoviárias e ferroviárias, aeroportos, instalações desportivas e de lazer. 


\begin{tabular}{|c|c|c|c|c|c|c|c|c|c|c|c|c|c|c|c|c|c|c|c|c|}
\hline \multirow{5}{*}{ 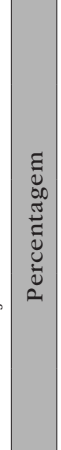 } & \multirow{5}{*}{ 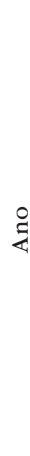 } & $\stackrel{\circ}{\circ}$ & $\begin{array}{l}n \\
f \\
f\end{array}$ & $\begin{array}{l}0 \\
\stackrel{2}{0}\end{array}$ & $\begin{array}{l}n \\
\hat{n} \\
0\end{array}$ & $\tilde{0}$ & $=$ & $\begin{array}{l}\Delta \\
0 \\
0\end{array}$ & $\begin{array}{l}\stackrel{0}{1} \\
\text { t. }\end{array}$ & $\begin{array}{l}\hat{\circ} \\
\infty\end{array}$ & $\stackrel{\infty}{0}$ & $\underset{-}{\stackrel{\sigma}{0}}$ & $\begin{array}{l}\hat{1} \\
\infty\end{array}$ & $\begin{array}{l}n \\
\tilde{n} \\
0 \\
-1\end{array}$ & $\begin{array}{l}\hat{\sigma} \\
+ \\
+\end{array}$ & $\begin{array}{l}\hat{N} \\
\hat{n}\end{array}$ & 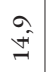 & & $\stackrel{\sim}{\sim}$ & 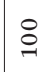 \\
\hline & & $\stackrel{n}{\approx}$ & $\begin{array}{c}\vec{n} \\
\vec{i}\end{array}$ & ô & $\begin{array}{l}n \\
0 \\
0\end{array}$ & $\vec{n}$ & & 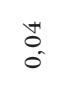 & $\begin{array}{l}\hat{A} \\
0\end{array}$ & $\stackrel{ \pm}{\stackrel{0}{0}}$ & $\stackrel{\leftrightarrow}{\rightarrow}$ & $\begin{array}{l}\vec{\infty} \\
i\end{array}$ & $\stackrel{n}{\stackrel{n}{6}}$ & $\begin{array}{l}0 \\
0 \\
0 \\
0\end{array}$ & $\begin{array}{l}\infty \\
\infty \\
\infty \\
\rightarrow\end{array}$ & $\begin{array}{l}0 \\
0 \\
0\end{array}$ & \begin{tabular}{l}
\multirow{0}{0}{} \\
$\approx$ \\
$\sim$
\end{tabular} & $\begin{array}{l}\stackrel{0}{\circ} \\
\stackrel{-}{\circ}\end{array}$ & 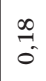 & $\stackrel{-}{\circ}$ \\
\hline & & $\begin{array}{l}\infty \\
\stackrel{\infty}{=}\end{array}$ & $\begin{array}{l}\stackrel{+}{0} \\
\stackrel{i}{i}\end{array}$ & : & $a^{n}$ & $\vec{n}$ & & $\stackrel{0}{0}_{0}^{*}$ & $\stackrel{\vec{i}}{\vec{i}}$ & $\begin{array}{l}\hat{n} \\
\approx \\
\approx\end{array}$ & $\begin{array}{l}\stackrel{0}{0} \\
\hat{0}\end{array}$ & $\begin{array}{l}n \\
\tilde{n} \\
\tilde{n}\end{array}$ & $\vec{n}$ & $\begin{array}{l}0 \\
-1 \\
n\end{array}$ & $\underset{\stackrel{+}{N}}{\stackrel{\sim}{N}}$ & है & $\begin{array}{l}\stackrel{+}{a} \\
\text { ठे }\end{array}$ & & $\overbrace{0}^{2}$ & 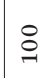 \\
\hline & & $\stackrel{+}{\stackrel{t}{2}}$ & $\stackrel{2}{=}$ & & $?_{0}^{n}$ & $\vec{n}$ & & $\begin{array}{l}\text { tu } \\
0 \\
0\end{array}$ & $\begin{array}{l}\stackrel{0}{2} \\
\stackrel{n}{n}\end{array}$ & $\stackrel{\sim}{\stackrel{2}{\sim}}$ & 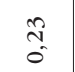 & $\begin{array}{l}\hat{\infty} \\
\hat{n}\end{array}$ & $\begin{array}{r}\vec{n} \\
\dot{n}\end{array}$ & 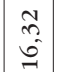 & \begin{tabular}{c}
\multirow{H}{*}{} \\
$\stackrel{8}{n}$
\end{tabular} & $\begin{array}{c}n \\
\hat{\sigma}\end{array}$ & $\partial$ & & $\stackrel{0}{\stackrel{+}{\sim}}$ & 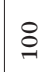 \\
\hline & & $\stackrel{1}{\varrho}$ & $\underset{-}{-}$ & & $\begin{array}{l}\hat{y} \\
\hat{0}\end{array}$ & $\vec{n}$ & & $\begin{array}{l}n \\
0 \\
0\end{array}$ & $\begin{array}{c}\stackrel{n}{\sim} \\
\tilde{n}\end{array}$ & 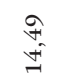 & तै & $\begin{array}{l}\stackrel{0}{0} \\
\dot{m}\end{array}$ & 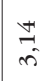 & $\mid$\begin{tabular}{l}
$\vec{\infty}$ \\
\multirow{-}{*}{}
\end{tabular} & $\begin{array}{l}\hat{n} \\
\vec{n}\end{array}$ & $\left|\begin{array}{l}\vec{t} \\
0 \\
\forall\end{array}\right|$ & $\begin{array}{l}\tilde{n} \\
\stackrel{\sim}{2} \\
\end{array}$ & & $\begin{array}{l}\hat{o} \\
\hat{i}\end{array}$ & 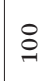 \\
\hline \multirow{5}{*}{ 苞 } & & $\stackrel{\circ}{\stackrel{2}{2}}$ & 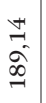 & กู & $\begin{array}{l}\stackrel{n}{\tilde{v}} \\
\vec{v}\end{array}$ & $\begin{array}{l}\hat{n} \\
\text { an }\end{array}$ & $\underset{f}{F}$ & 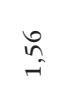 & $\underset{⿱}{\stackrel{+}{*}}$ & 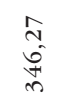 & $\begin{array}{l}\infty \\
\stackrel{\infty}{ } \\
\infty \\
m\end{array}$ & $\begin{array}{l}\tilde{n} \\
\tilde{f}\end{array}$ & $\begin{array}{l}\infty \\
0 \\
\hat{0} \\
\sim\end{array}$ & 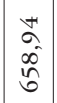 & $\begin{array}{l}\vec{N} \\
\overrightarrow{-} \\
\stackrel{-}{7}\end{array}$ & $\left|\begin{array}{c}+ \\
\infty \\
\infty \\
\infty \\
\sim \\
N\end{array}\right|$ & $\begin{array}{l}\hat{n} \\
\hat{n} \\
\hat{n}\end{array}$ & & \begin{tabular}{l}
$n$ \\
$n$ \\
$\infty$ \\
\multirow{+}{*}{}
\end{tabular} & $\begin{array}{l}\vec{n} \\
10 \\
0 \\
0\end{array}$ \\
\hline & \multirow{3}{*}{$\stackrel{8}{\gtrless}$} & $\stackrel{n}{\partial}$ & $\begin{array}{l}n \\
\infty \\
2 \\
a\end{array}$ & $\begin{array}{l}\text { ¿t } \\
\text { nd }\end{array}$ & $\begin{array}{l}\vec{z} \\
\vec{z}\end{array}$ & $\begin{array}{l}\stackrel{+}{n} \\
\stackrel{n}{*}\end{array}$ & & $\stackrel{\vec{n}}{=}$ & $\begin{array}{l}\text { in } \\
\text { in } \\
\text { in }\end{array}$ & $\begin{array}{l}\stackrel{2}{*} \\
\stackrel{+}{+}\end{array}$ & $\begin{array}{l}\text { के } \\
\text { ¿n. } \\
\text { in }\end{array}$ & $\stackrel{\partial}{\exists}$ & $\begin{array}{l}\circ \\
\stackrel{0}{0} \\
\stackrel{0}{0}\end{array}$ & 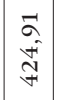 & $\begin{array}{l}\tilde{N} \\
\stackrel{\vec{N}}{N}\end{array}$ & 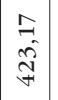 & $\begin{array}{l}\hat{0} \\
\text { ते } \\
\text { ă }\end{array}$ & 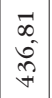 & $\stackrel{\pi}{r}$ & $\begin{array}{l}\vec{n} \\
10 \\
\infty \\
\text { nे }\end{array}$ \\
\hline & & $\stackrel{\infty}{\stackrel{\infty}{\sigma}}$ & $\vec{n}$ & $\overrightarrow{\tilde{N}}$ & $\stackrel{\infty}{=}$ & $\begin{array}{l}\mathbb{Z} \\
\stackrel{ \pm}{a}\end{array}$ & & $\stackrel{\bullet}{:}$ & $\begin{array}{l}\bar{n} \\
\hat{b} \\
\infty\end{array}$ & 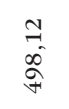 & $\frac{\infty}{0}$ & 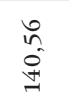 & $\begin{array}{l}\stackrel{+}{r} \\
\vec{N}\end{array}$ & $\begin{array}{c}n \\
0 \\
f \\
0 \\
0\end{array}$ & $\stackrel{\circ}{\circ}$ & $\overrightarrow{\vec{n}}$ & 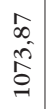 & & 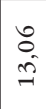 & 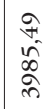 \\
\hline & & $\stackrel{+}{\stackrel{N}{\leftrightarrows}}$ & $\begin{array}{l}0 \\
\infty \\
\infty \\
0 \\
0\end{array}$ & & $\begin{array}{l}\infty \\
\stackrel{2}{=} \\
=\end{array}$ & \begin{tabular}{l}
\multirow{A}{*}{} \\
$\stackrel{1}{\approx}$
\end{tabular} & & $\stackrel{\circ}{\stackrel{2}{\sim}}$ & $\begin{array}{l}n \\
\stackrel{n}{ \pm} \\
-\end{array}$ & $\begin{array}{l}\infty \\
\stackrel{1}{n} \\
\tilde{N} \\
i\end{array}$ & $a^{2}$ & $\begin{array}{l}\hat{n} \\
i n \\
n\end{array}$ & $\begin{array}{l}\hat{-} \\
\stackrel{-}{*}\end{array}$ & $\begin{array}{l}5 \\
0 \\
0 \\
0 \\
0\end{array}$ & $\begin{array}{l}\stackrel{\vec{t}}{1} \\
\vec{I} \\
\vec{J}\end{array}$ & $\left|\begin{array}{l}+1 \\
2 \\
2 \\
2 \\
2\end{array}\right|$ & 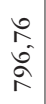 & & $\begin{array}{l}n \\
\infty \\
\infty \\
n\end{array}$ & $\begin{array}{l}\infty \\
+ \\
10 \\
\infty \\
\infty\end{array}$ \\
\hline & & $\begin{array}{l}\text { ¿ } \\
\stackrel{2}{\sigma}\end{array}$ & \begin{tabular}{l}
$\vec{i}$ \\
\multirow{0}{*}{}
\end{tabular} & & $\begin{array}{l}\hat{n} \\
\stackrel{0}{0}\end{array}$ & $\begin{array}{l}\infty \\
\stackrel{\infty}{\sim} \\
\stackrel{\sim}{\sim}\end{array}$ & & 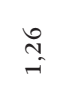 & 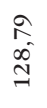 & $\begin{array}{l}\hat{n} \\
\hat{n} \\
i n\end{array}$ & $\begin{array}{l}\vec{r} \\
\infty\end{array}$ & \begin{tabular}{l}
$n$ \\
0 \\
0 \\
\multirow{0}{*}{} \\
-1
\end{tabular} & $\begin{array}{l}\stackrel{0}{=} \\
\stackrel{n}{\sim}\end{array}$ & $\begin{array}{c}n \\
\hat{n} \\
0 \\
\hat{n} \\
i\end{array}$ & $\begin{array}{l}n \\
\hat{n} \\
\stackrel{0}{0} \\
\stackrel{3}{N}\end{array}$ & $\vec{\Xi}$ & $\overrightarrow{0}$ & & $\begin{array}{l}N \\
\infty \\
\infty\end{array}$ & $\begin{array}{l}n \\
10 \\
\infty \\
\hat{n}\end{array}$ \\
\hline \multirow{5}{*}{ 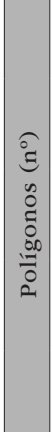 } & & $\stackrel{0}{\circ}$ & $\stackrel{2}{N}$ & $N$ & 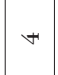 & $\rightarrow$ & - & - & $a$ & $\ddot{n}$ & $\stackrel{\partial}{-}$ & $\stackrel{\bullet}{\sim}$ & ส & $\vec{n}$ & $\underset{\forall}{*}$ & $\stackrel{\circ}{+}$ & in & & $N$ & $\vec{n}$ \\
\hline & \multirow{4}{*}{ ஓ } & $\approx \approx$ & $\stackrel{\Delta}{N}$ & $N$ & - & $\rightarrow$ & & - & $\stackrel{\circ}{\sim}$ & $\vec{n}$ & $\beth$ & $\stackrel{\wedge}{\sim}$ & ส & $\stackrel{\infty}{\sim}$ & $\vec{n}$ & $\stackrel{n}{\sim}$ & 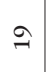 & $n$ & - & $\underset{\sim}{\sim}$ \\
\hline & & $\stackrel{\infty}{\stackrel{\infty}{二}}$ & $\hat{N}$ & $r$ & - & - & & - & $\Rightarrow$ & $\ddot{n}$ & \pm & 아 & $\approx$ & $\stackrel{\sim}{*}$ & $\underset{\forall}{*}$ & $\hat{n}$ & 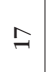 & & - & $\stackrel{n}{\sim}$ \\
\hline & & 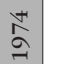 & $\grave{N}$ & & - & - & & - & $\stackrel{?}{-}$ & $\stackrel{\star}{\sim}$ & 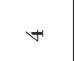 & $\hat{n}$ & ก & $\tilde{\sim}$ & f & ৯े & \pm & & - & $\stackrel{\stackrel{\circ}{\sim}}{\sim}$ \\
\hline & & $\begin{array}{l}\stackrel{n}{2} \\
ٍ\end{array}$ & $\stackrel{\infty}{\sim}$ & & - & - & & - & $\stackrel{\bullet}{\sim}$ & $\stackrel{\sim}{\sim}$ & 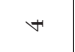 & $\hat{n}$ & $\cong$ & $\tilde{\mathrm{N}}$ & $\stackrel{\mathrm{v}}{ }$ & $\stackrel{\sim}{\sim}$ & $\approx$ & & - & $\vec{\sim}$ \\
\hline 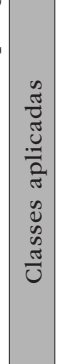 & & & 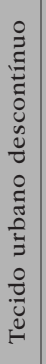 & 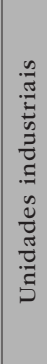 & 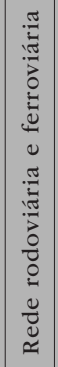 & 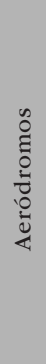 & 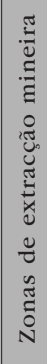 & 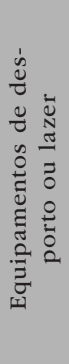 & 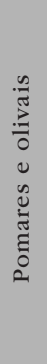 & 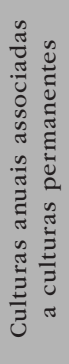 & 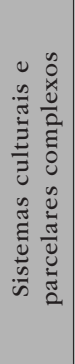 & 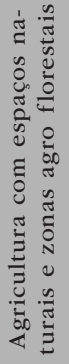 & $\begin{array}{l}0 \\
\tilde{y} \\
0 \\
0 \\
0 \\
0 \\
0 \\
0 \\
0 \\
\tilde{J} \\
\tilde{0} \\
0 \\
0 \\
\frac{0}{x}\end{array}$ & 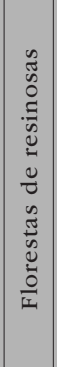 & 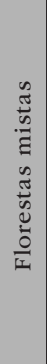 & 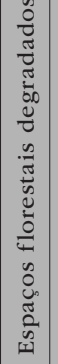 & $\frac{\tilde{\theta}}{\stackrel{0}{\pi}}$ & 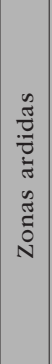 & 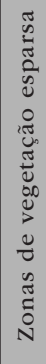 & مَّ \\
\hline
\end{tabular}


Os dados também mostram o crescimento de um padrão complexo e uma dinâmica que reforça as mudanças gerais na área de estudo como um todo. A Figura 4 mostra a evolução das subclasses das dezassete classes de uso e ocupação do solo na área de estudo no período em análise, revelando um aumento de áreas artificiais em contraste com a diminuição contínua das áreas agrícolas. Cerca de $27 \%$ da área de estudo é genericamente representada pelos espaços antropizados, urbanos e agrícolas, de uma forma consistente ao longo do período de análise, remetendo as restantes transformações para os espaços florestais e naturais.

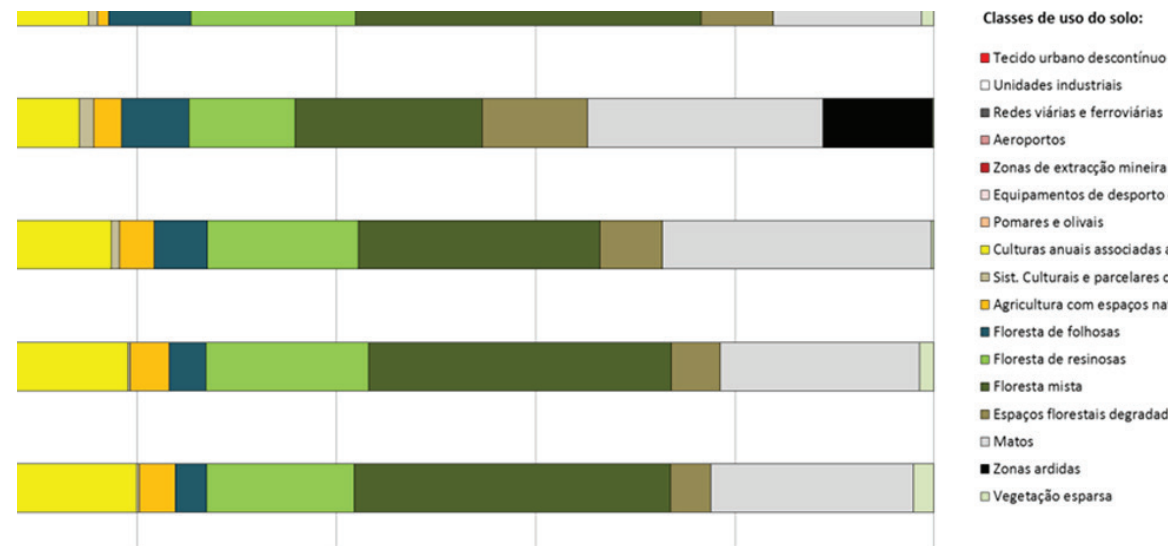

Figura 4 - Representação das classes de uso e ocupação do solo de 1965 até 2010 na área de estudo

\section{ANÁlise dinÂMICA dAS MUdANÇAS DE USO E OCUPAÇÃo DO SOLO NA} ÁREA DE ESTUdo

As matrizes de transformação para 1965-1974, 1974-1983, 1983-1995, 1995-2010 e posteriormente para 1965-2010, permitiram um estudo detalhado da dinâmica de mudança no uso e ocupação do solo em cinco períodos de análise (Figura 5). O grau de estabilidade (GE) da cobertura do solo foi calculado para cada matriz de transformação (o quociente entre a soma das áreas cujo uso ou ocupação não se alterou e a área total) (Eq. (A3)).

A Figura 5 ilustra a dinâmica do uso e ocupação do solo nos diferentes 
períodos, salientando os vectores a transformação visual entre as classes. As trajectórias revelam aspectos distintos para os diferentes períodos. $\mathrm{O}$ indicador de estabilidade global apresenta valores contrastantes variando de 38,18 \% (no período 1995-2010) até 65,40\% (no período 1965-1974). Os dados exibem uma sequência contínua em que o grau de estabilidade diminui de 1965 até 2010. Nos períodos de 1965-1974 e 1974-1983, os graus de estabilidade são bastante semelhantes $(65,40 \%$ e $61 \%)$, mas em 1983-1995 o GE diminui em cerca de 12 \%, tal como no período 19952010, onde existe uma diminuição de cerca de 11\% em comparação com o período anterior. Isto significa que as maiores transições no uso e ocupação do solo na área de estudo efectuaram-se a partir de 1983 (Figura 6).

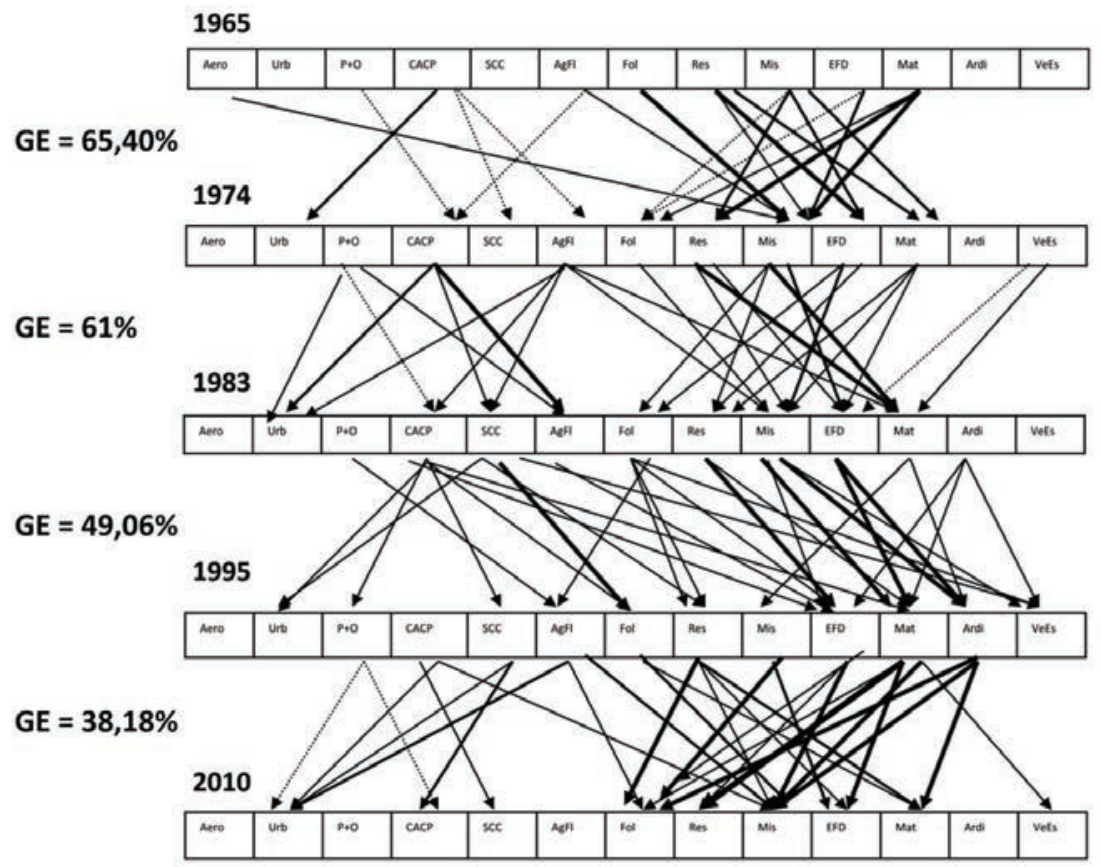

Aero: Aeródromo; Urb: Tecido urbano descontínuo + Unidades industriais + Redes rodoviárias e ferroviárias + Zonas de extracção mineira + Equipamentos de desporto e lazer; P+O: Pomares e olivais; CACP: Culturas anuais associadas a culturas permanentes; SCC: Sistemas culturais e parcelares complexos; AgFl: Agricultura com espaços naturais e zonas agro-florestais; Fol: Floresta de folhosas; Res: Floresta de resinosas; Mis: Floresta mista; EFD: Espaços florestais degradados; Mat: Matos; Ardi: Zonas ardidas; VeEs: Zonas de vegetação esparsa

Figura 5 - Transformações dinâmicas de uso e ocupação do solo e grau de estabilidade (GE) para cada período analisado 


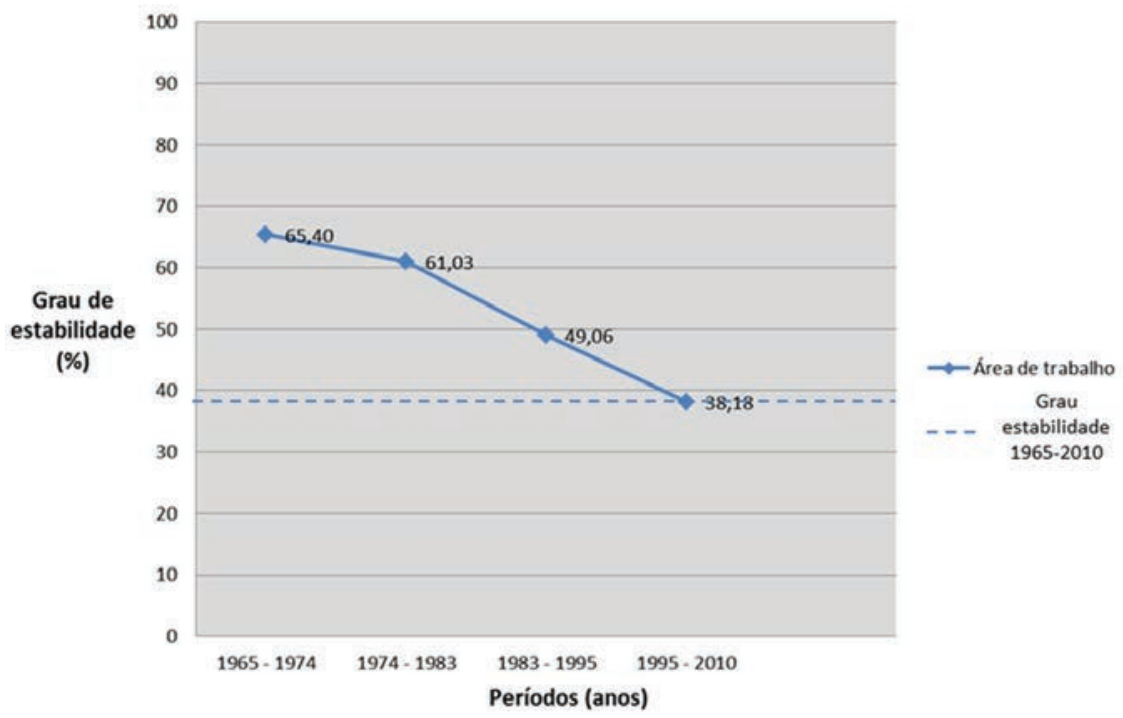

Figura 6 - Comparação dos diferentes graus de estabilidade para a área de estudo no período 1965-2010

Os resultados mostram assim que há três etapas que podem ser identificadas na evolução do uso e ocupação do solo entre 1965 e 2010: em primeiro lugar, no período 1965-1983, em que há uma elevada estabilidade entre todas as classes de uso, com as grandes transformações a ocorrem em dois domínios: áreas florestais e áreas artificiais/agrícolas; o segundo e terceiro períodos, 1983-1995 e 1995-2010, apresentam um grau de estabilidade mais moderado e são caracterizados essencialmente por uma alteração na tipologia florestal, e com ganhos da área urbana a partir de espaços agro-florestais.

A análise compósita reforça o baixo grau de estabilidade (GE) de 39,33\% para a totalidade do período analisado, o que reflecte a consistência das classes de mudança, em que $61,77 \%$ da área foi alterada, com uma dinâmica intensa de transformação do solo, no período estudado (1965-2010).

Esta avaliação reflecte um aumento contínuo das áreas artificiais, a partir de núcleos urbanos pré-existentes e infra-estruturas rodoviárias. Os terrenos agrícolas são a maior área de origem das superfícies artificiais dando-se esta transformação, principalmente, na parte ocidental da área. As áreas agrícolas também servem de suporte para o incremento 
gradual das florestas e áreas naturais, em particular nos sectores norte e oeste da área de estudo.

\section{TRANSFORMAÇÕES SISTEMÁTICAS E CASUÍSTICAS DE USO E OCUPAÇÃO DO SOLO}

A área de estudo apresenta uma área predominantemente florestal no sector sul e uma forma de ocupação urbana na zona noroeste. As principais mudanças ocorreram na seção noroeste da área, envolvendo o crescimento urbano, uma diminuição das áreas agrícolas e o desenvolvimento de áreas florestais.

Dois processos de transformações sistemáticos de uso e ocupação do solo podem ser identificados: um relacionado com a urbanização e a degradação de áreas agrícolas, representada por um aumento acumulado de áreas artificiais, e outro, relacionado com a transformação consistente de tipologia e padrões florestais e áreas de vegetação esparsa, o qual é denominado de rotação das características da floresta.

A análise dos três parâmetros (a) transformações das classes de uso, (b) grau de estabilidade e (c) intercâmbio entre a floresta e as áreas de vegetação esparsa e áreas agrícolas e artificiais, permite destacar: (1) o período de 1965-1974, em que há um alto grau de estabilidade de uso e ocupação do solo e a transformação entre a floresta e as áreas de vegetação esparsa e áreas agrícolas e artificiais é limitado; o período de 1974-1983, que também revela um alto grau de estabilidade e um baixo intercâmbio entre floresta e áreas de vegetação esparsa e áreas agrícolas e artificiais, mas também a degradação das florestas, envolvendo um aumento dos espaços florestais degradados e dos matos; (2) o período de 1983凶1995, que mostra um moderado grau de estabilidade e um aumento na floresta e áreas de vegetação esparsa, assim como a degradação da tipologia florestal, reflectida num aumento nas áreas florestais degradadas, matos e áreas ardidas; (3) o período de 1995-2010, que apresenta um baixo grau de estabilidade, onde as grandes transformações estão associadas à transição florestal, envolvendo uma profunda mudança na tipologia e padrões da floresta e um incremento de área da floresta de 
folhosas, resinosas e mista.

Como transformações de uso e ocupação do solo casuísticas na área de estudo podem-se considerar as áreas ardidas, com evidência nas imagens de 1995 (reflexo de incêndios em 1990 e 1995), e a exploração de recursos minerais, a partir de 1995.

$\mathrm{Na}$ transformação de uso e ocupação do solo podem ser considerados forçadores vários instrumentos de gestão territorial, nomeadamente pelo Plano Director Municipal de 1993, enquadrando o crescimento urbano verificado em 2010, assim como os regimes de protecção RAN (1991) e REN (1993) ou instrumentos de gestão florestal de 1998 e 2006, que consubstanciam os processos de transformação no espaço florestal.

\section{CONCLUSÕES}

Os resultados globais para a área de estudo confirmam uma transição geral, com processos que podem ser considerados sistemáticos, correspondendo a trajectórias casuísticas apenas o caso das classes de uso e ocupação do solo resultantes de incêndios florestais inesperados ou o surgimento de zonas de extracção mineral para a indústria de construção.

Observa-se na área de estudo uma elevada alteração de uso e ocupação do solo (grau de estabilidade (GE) de 39,33\%), reflectindo quer transformações sistemáticas, quer transformações isoladas (casuísticas). O valor do grau de estabilidade é progressivamente menor, apresentando valores menores nos espaços temporais mais recentes (1983-1995) e (1995-2010).

Emergem na dinâmica de transformação de uso e ocupação do solo a urbanização com degradação das áreas agrícolas, assim como os processos de evolução da tipologia e padrões florestais e das áreas com vegetação esparsa.

A perda de áreas agrícolas para zonas com ocupação urbana é também evidente nesta área, como em muitos outros exemplos identificados por diferentes autores (KAZANKO et al., 2006; SU et al., 2011), reflectindo as transformações identificadas em Portugal (FREIRE et al., 2009;. JONES et al., 2011; TAVARES et al., 2012). Observa-se na área um aumento da 
heterogeneidade no uso e ocupação do solo, o que corresponde a uma evolução dos padrões e de evolução dos indicadores dos espaços rurais (HASSE \& LATHROP, 2003; BODESMO et al., 2012).

\section{AGRADECIMENTOS}

Este estudo foi apoiado pelo projecto "SCRAM - Crises, gestão de risco e novos arranjos sócio-ecológicos para florestas - uma perspectiva dos estudos sobre ciência e tecnologia" (PTDC/CS-ECS/102041/2008 FCOMP-01-0124-FEDER-009236), financiado pela Fundação para a Ciência e Tecnologia (FCT). Os autores agradecem a Eugenia Rodrigues e aos gestores locais dos Baldios de Vilarinho pelo contínuo apoio no fornecimento de informações locais e históricas, bem como das valiosas contribuições na discussão dos resultados do estudo. Agradece-se também ao António Patrão pelas valiosas contribuições sobre o histórico de ocorrências de incêndios florestais e planos de gestão da região.

\section{BIBLIOGRAFIA:}

ABDULLAH, Saiful \& NAKAGOSHI, Nobukazu (2008) - "Changes in agricultural landscape pattern and its spatial relationship with forestland in the State of Selangor, peninsular Malaysia”. Landscape and Urban Planning, Vol.87, 147-155. Disponível online no endereço url: http://www.sciencedirect. com/science/article/pii/S0169204608000844 (acedido em 12 Março, 2014).

ASPINALL, Richard (2004) - "Modelling land use change with generalized linear models e a multi-model analysis of change between 1860 and 2000 in Gallatin Valley, Montana”. Journal of Environmental Management, Vol.72, 91-103. Disponível online no endereço url: http://www.sciencedirect.com/ science/article/pii/S0301479704000805\# (acedido em 12 Março, 2014).

AZEVEDO, João et al. (2011) - "Agriculture abandonment, land-use change and fire hazard in mountain landscapes in Northeastern Portugal”, in LI, Chao; LAFORTEZZA, Raffaele \& CHEN, Jiquan (eds.): Landscape Ecology in Forest Management and Conservation: Challenges and Solutions for Global Change, HEP-Springer, Beijing, 329-351. Disponível online no endereço url: https:// bibliotecadigital.ipb.pt/bitstream/10198/2945/1/Chapter14abstractsmall.pdf

Conservation: Challenges and Solutions for Global Change, HEP-Springer, Beijing, 329-351. Disponível online no endereço url: https://bibliotecadigital.ipb. pt/bitstream/10198/2945/1/Chapter14abstractsmall.pdf (acedido em 12 
Março, 2014).

BODESMO, Mara et al. (2012) - "The role of environmental and socio.demographic indicators in the analysis of land use changes in a protected area of the Natura 2000 Network: the case study of Lake Trasimeno, Umbria, Central Italy". Environ Monit Assess, Vol.184, 831-843. Disponível online no endereço url: http://link.springer.com/article/10.1007/s10661-011-2004-z (acedido em 12 Março, 2014).

BOSSARD, Michel et al. (2000) - Corine land cover technical guide - Addendum. Technical Report No 40. Copenhagen: EEA, 105 p. Disponível online no endereço url: http://www.dmu.dk/fileadmin/Resources/DMU/Udgivelser/ CLC2000/technical_guide_ad denum.pdf (acedido em 12 Março, 2014).

BRAIMOH, Ademola (2006) - "Random and systematic land-cover transitions in northern Ghana". Agriculture, Ecosystems and Environment, Vol.113, $\mathrm{N}^{\circ}$ 1-4, 254-263. Disponível online no endereço url: http://www.sciencedirect. com/science/article/pii/S0167880905005001 (acedido em 12 Março, 2014).

BRAIMOH, Ademola, \& ONISHI, Takashi (2007) - "Spatial determinants of urban land use change in Lagos, Nigeria”. Land Use Policy, Vol.24, $\mathrm{N}^{\circ} 2$, 502-515. Disponível online no endereço url: http://www.sciencedirect.com/science/ article/pii/S0264837706000846 (acedido em 12 Março, 2014).

CASTANHEIRA, José \& ARANHA, José (2004) - "Estudo da alteração da cobertura do solo no Vale do Alto Tâmega. Estudo multi-temporal com imagens Landsat-5 TM e Landsat-7 ETM+." In VIII Encontro de utilizadores de Sistemas de informação geográfica, Oeiras, Portugal.

CATAlAN, Bibiana et al. (2008) - "Urban Sprawl in the Mediterranean? Patterns of Growth and Change in the Barcelona Metropolitan Region 1993-2000". Landscape and Urban Planning, Vol.85, N³-4, 174-184. Disponível online no endereço url: http://www.sciencedirect.com/science/article/pii/ S0169204607002848 (acedido em 12 Março, 2014).

CLAESSENS, Lieven et al. (2009) - "Modelling interactions and feedback mechanism between land use change and landscape processes". Agriculture, Ecosystem and Environment, Vol.129, $\mathrm{N}^{\circ}$ 1-3, 157-170. Disponível online no endereço url: http://www.sciencedirect.com/science/article/pii/S0167880908002417 (acedido em 12 Março, 2014).

DIOGO, Vasco, \& KOOMEN, Eric (2012) - "Land-use change in Portugal, 19902006: main processes and underlying factors". Cartographica, Vol. 47, N 4 , 237-249. doi: 10.3138/carto.47.4.1504. Disponível online no endereço url: http://eds.a.ebscohost.com/ehost/pdfviewer/pdfviewer?sid=521d58fc-56024731-ad56- 643e809fe63b\%40sessionmgr4001\&vid=2\&hid=4108 (acedido em 8 Março, 2014).

DOMON, Gérald (2011) - "Landscape as resource: Consequences, challenges and opportunities for rural development”. Landscape and Urban Planning, 
Vol. 100, Nº 4, 338-340. doi:10.1016/j.landurbplan.2011.02.014. Disponível online no endereço url: http://www.sciencedirect.com/science/article/pii/ S0169204611000727 (acedido em 8 Março, 2014).

EEA (1990) - Corine Land Cover (CLC1990) $100 \mathrm{~m}$ - version 12/2000. Agência Ambiental Europeia. Disponível online no endereço url: http://www.eea. europa.eu/data.and- maps/data (acedido em 8 Março, 2014).

FIGUEIREDO, Tomás et al. (2012) - "Degradação física do solo em áreas queimadas de matos no nordeste transmontano". In Fórum CIMO - Ciência e Desenvolvimento 2012, Bragança, Portugal. Disponível online no endereço url: https://bibliotecadigital.ipb.pt/bitstream/10198/9000/1/Figueiredo\% 20et\%20al.\%20Foru mCIMO_2012.pdf (acedido em 9 Março, 2014).

FREIRE, Sérgio et al. (2009) - "Recent urbanization and land use/land cover change in Portugal - the influence of coastline and coastal urban centers". Journal of Coastal Research, Vol. 56, Special Issue, 1499-1503. Disponível online no endereço url: http://www.jstor.org/discover/10.2307/25738039?uid= 3738880\&uid=2\&uid=4\&sid=2110 3727182887 (acedido em 8 Março, 2014).

HARA, Yuji et al. (2005) - "Urbanization linked with past agricultural landuse patterns in the urban fringe of a deltaic Asian mega.city: A case studying Bangkok". Landscape and Urban Planning, Vol. 73, №1, 16-28. Disponível online no endereço url: http://www.sciencedirect.com/science/article/pii/ S0169204604000933 (acedido em 8 Março, 2014).

HASSE, John, \& LATHROP, Richard (2003) - "Land resource impact indicators of urban sprawl”. Applied Geography, Vol. 23, No 2-3, 159.175. Disponível online no endereço url: http://www.sciencedirect.com/science/article/pii/ S0143622803000158 (acedido em 8 Março, 2014).

HIETEL, Elke et al. (2004) - "Analysing land-cover changes in relation to environmental variables in Hesse, Germany”. Landscape Ecology, Vol. 19, N ${ }^{\circ}$, 473-489. Disponível online no endereço url: http://link.springer.com/ article/10.1023/B:LAND.0000036138.82213.80 (acedido em 8 Março, 2014).

INE (2012) - Censos 2011 Resultados Definitivos - Portugal. Instituto Nacional de Estatística, Lisboa, 559 p. Disponível online no endereço url: http://www. ine.pt/xportal/xmain?xpid=INE\&xpgid=ine_publicacoes\&PUBLICACOESpub_b oui $=73212469 \&$ PUBLICACOEStema $=55466 \&$ PUBLICACOESmodo $=2$ (acedido em 8 Março, 2014).

JONES, Nádia et al. (2011) - "Historical review of land use changes in Portugal (before and after EU integration in 1986) and their implications for land degradation and conservation, with a focus on Centro and Alentejo regions". Applied Geography, Vol. 31, No3, 1036-1048. Disponível online no endereço url: http://www.sciencedirect.com/science/article/pii/S0143622811000385 (acedido em 10 Março, 2014). 
KASANKO, Marjo et al. (2006) - "Are European cities becoming dispersed? A comparative analysis of 15 European urban areas". Landscape and Urban Planning, Vol. 77, $N^{\circ}$ 1-2, 111-130. Disponível online no endereço url: http:// www.sciencedirect.com/science/article/pii/S0169204605000332 (acedido em 10 Março, 2014).

KOLIOS, Stavros, \& STYLIOS, Chrysostomos (2013) - "Identification of land cover/ land use changes in the greater area of the Preveza peninsula in Greece using Landsat satellite data". Applied Geography, Vol. 40, 150-160. Disponível online no endereço url: http://www.sciencedirect.com/science/article/pii/ S0143622813000568 (acedido em 10 Março, 2014).

LASANTA, Teodoro et al. (2006) - "Using landscape ecology to evaluate an alternative management scenario in abandoned Mediterranean mountain areas”. Landscape and Urban Planning, Vol. 78, $\mathrm{N}^{\circ}$ 1-2, 101-114. Disponível online no endereço url: http://www.sciencedirect.com/science/article/pii/ S0169204605000812 (acedido em 9 Março, 2014).

LI, Xiaoma et al. (2013) - "Forty years of urban expansion in Beijing: What is the relative importance of physical, socioeconomic, and neighborhood factors?” Applied Geography, Vol. 38, 1-10. Disponível online no endereço url: http://www.sciencedirect.com/science/article/pii/S0143622812001294 (acedido em 10 Março, 2014).

MANANDHAR, Ramita et al. (2010) - "Analysis of twenty years of categorical land transitions in the lower hunter of new South Wales, Australia". Agriculture, Ecosystems and Environment, Vol. 135, N4, 336-346. Disponível online no endereço url: http://www.sciencedirect.com/science/article/pii/ S0167880909003193 (acedido em 10 Março, 2014).

NÉRY, Fernanda (2007) - Nomenclatura CORINE Land Cover: versão portuguesa comentada. Instituto Geográfico Português, Lisboa, 105 p.

NUNES, Adélia et al. (2011) - "Impacts of land use and cover type on runoff and soil erosion in a marginal area of Portugal”. Applied Geography, Vol. 31, $\mathrm{N}^{\circ}$ 2, 687-699. doi: 10.1016/j.apgeog.2010.12.006. Disponível online no endereço url: http://www.sciencedirect.com/science/article/pii/S014362281000175X (acedido em 10 Março, 2014).

PIWOWAR, Joseph (2005) - "Digital image analysis", in ARONOFF, Stanley (Ed.), Remote sensing, Redlands, California: ESRI Press, 287-335.

PÔÇAS, Isabel et al. (2011) - "Remote sensing based indicators of changes in a mountain rural landscape of northeast Portugal”. Applied Geography, Vol. 31, No3, 871-880. Disponível online no endereço url: http://www.sciencedirect. com/science/article/pii/S0143622811000154 (acedido em 10 Março, 2014).

ROZENSTEIN, Offer, \& KARNIELI, Arnon (2011) - "Comparison of methods for land-use classification incorporating remote sensing and GIS inputs". Applied Geography, Vol. 31, No2, 533-544. Disponível online no endereço 
url: http://www.sciencedirect.com/science/article/pii/S0143622810001517 (acedido em 10 Março, 2014).

RUDEL, Thomas et al. (2005) - "Forest transitions: towards a global understanding of land use change". Global Environment Change, Vol. 15, Nº 1, 23-31. doi: 10.1016/j.gloenvcha.2004.11.001. Disponível online no endereço url: http:// www.sciencedirect.com/science/article/pii/S0959378004000809 (acedido em 10 Março, 2014).

SOARES, António et al. (2007) - Carta Geológica de Portugal, esc. 1/50000, 19-D, Coimbra - Lousã. Notícia Explicativa, Departamento de Geologia, I.N.E.T.I., Lisboa, $71 \mathrm{p}$.

SU, Shiliang et al. (2011) - "Transformation of agricultural landscapes under rapid urbanization: a threat to sustainability in Hang-Jia-Hu region, China”. Applied Geography, Vol. 31, N², 439-499. Disponível online no endereço url: http://www.sciencedirect.com/science/article/pii/S0143622810001232 (acedido em 10 Março, 2014).

TAPIADOR, Francisco, \& CASANOVA, Jose (2003) - "Land use mapping methodology using remote sensing for the regional planning directives in Segovia, Spain”. Landscape and Urban Planning, Vol. 62, N², 103-115. Disponível online no endereço url: http://www.sciencedirect.com/science/article/pii/ S0169204602001263 (acedido em 10 Março, 2014).

TAVARES, Alexandre et al. (2012) - "Spatial and temporal land use change and occupation over the last half century in a peri-urban area”. Applied Geography, Vol. 34, 432-444. Disponível online no endereço url: http:// www.sciencedirect.com/science/article/pii/S0143622812000112 (acedido em 10 Março, 2014).

VERBURG, Peter et al. (2010) - "Trajectories of land use change in Europe: a model-based exploration of rural futures". Landscape Ecology, Vol. 25, 217232. Disponível online no endereço url: http://link.springer.com/article/1 0.1007\%2Fs10980-009-9347-7 (acedido em 12 Março, 2014).

WENTZ, Elizabeth et al. (2006) - "Land use and land cover mapping from diverse data sources for an arid urban environments". Computers, Environment and Urban Systems, Vol. 30, No3, 320-346. Disponível online no endereço url: http://www.sciencedirect.com/science/article/pii/S0198971504000511 (acedido em 10 Março, 2014). 
Série Documentos

Imprensa da Universidade de Coimbra

Coimbra University Press

2015

- U M

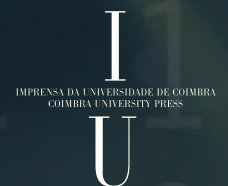

